\title{
Contribuições da visão baseada em recursos com o processo estratégico tradicional em uma empresa de consultoria ambiental
}

\author{
Contributions of the resource based view with the \\ traditional strategic process of an environmental \\ consulting
}

\author{
Marcelo Hugo de Medeiros Bezerra ${ }^{1}$ \\ Miguel Eduardo Moreno Añez ${ }^{2}$ \\ Josué Vitor de Medeiros Júnior ${ }^{3}$ \\ César Augusto Barreto da Silva ${ }^{4}$
}

\section{Resumo}

Este estudo teve como objetivo identificar as contribuições da Visão Baseada em Recursos no processo estratégico tradicional de uma empresa de consultoria ambiental. Para tanto, os recursos estratégicos da organização foram identificados por meio da metodologia VRIO, a partir de entrevistas semiestruturadas com os gestores da organização. Como resultado, foram identificadas quais as etapas realizadas no processo de planejamento estratégico da organização integrando a VBR e o processo tradicional. Como conclusão do estudo, constatou-se que a escola do posicionamento e a Visão Baseada em Recursos podem ser usadas de uma maneira integrada na formulação e implementação estratégica, com o objetivo de potencializar características de cada corrente estratégica e explorando oportunidades do ambiente organizacional e os recursos estratégicos como fontes de vantagem competitiva. Como perspectiva futura, espera-se que a abordagem

Bacharel em Administração pela UFRN. Técnico em Controle Ambiental pelo IFRN - Brasil E-mail: marcelohugu@hotmail.com

2 Professor Titular pelo Departamento de Administração da UFRN e Pós- Doutor em Administração Internacional pelo Centro Detudes em AdministrationInternacionale da Ėcole Des HautesĖtudesCommerciles (HEC), Universite de Montréal, (Canadá) - Brasil - E-mail: anez1957@yahoo.com.br

3 Doutor e Mestre em Administração pela UFRN. Professor de Administração da UFRN - Brasil E-mail: josuevitor16@gmail.com

4 Mestre em Administração pela UFRN - Brasil - E-mail: cesarmkt@gmail.com 
apresentada neste trabalho seja amplamente discutida e explorada, a fim de atender às demandas e oportunidades do mercado.

Palavras-chave: Estratégia empresarial. Planejamento estratégico. Processo estratégico. Visão Baseada em Recursos. Balanced Scorecard.

\begin{abstract}
The present study aimed to identify the contributions of the Resource Based View in the strategic process of an environmental consulting. For this purpose, the strategic resources of the organization were identified through the methodology VRIO through semi-structured interviews with the manager of the organization. As a result, the steps performed in the organization's strategic planning processintegrating the RBV and the traditional process. In conclusion, the positioning and the Resource Based View can be used in an integrated manner in the formulation and implementation of strategic, aiming to enhance the characteristics of each current strategic and exploring environmental opportunities and organizational resources strategic sources of competitive advantage. As a future perspective, it is expected that the approach presented in this work will be widely discussed and explored in order to meet the demands and market opportunities.
\end{abstract}

Keywords:Business Strategy. Strategic Planning.Strategic Process. Resource Based View.Balanced Scorecard.

\title{
1 Introdução
}

A literatura estratégica, ao longo dos anos, a partir da análise da vantagem competitiva, busca explicar quais são as fontes geradoras de taxas de retorno acima do normal e desenvolver frameworks com o intuito de as organizações identificarem e explorarem tais fontes que as diferenciam das demais concorrentes (KRETZER; MENEZES, 2006).

As teorias da estratégia organizacional que tratam de questões relacionadas à vantagem competitiva podem ter dois enfoques principais (VASCONCELOS; CYRINO, 2000): um que contextualiza a vantagem como um atributo de posicionamento, portanto, exterior à organização e relacionado à dinâmica de mercado, influenciada pelos trabalhos de Porter (1980, 1985); e outro que enfatiza as características internas da organização como principais responsáveis pelo desempenho superior e, 
consequentemente, causadores de uma vantagem competitiva em longo prazo, sendo tal pensamento iniciado pelo trabalho de Penrose (1959) e definido como Visão Baseada em Recursos (VBR).

Dentre os dois enfoques, a ideia de que a vantagem competitiva advém de um posicionamento específico dentro de um determinado mercado/indústria predomina nos estudos da estratégia. Reconhecidamente, tal foco baseado em uma posição privilegiada vem recebendo críticas constantes como sendo a única fonte de retornos acima do normal para uma organização (BARNEY, 1986; DIERICKX; COOL, 1989; GRÖBLER, 2007; KRETZER; MENEZES, 2006; WERNEFELT, 1984).

Além disso, Gohr et al. (2011) enfatizam que as organizações se contentam com uma análise superficial dos seus pontos fortes e fracos por meio de metodologias como a análise SWOT, em vez de atentarem para o desenvolvimento dos recursos que causam um diferencial competitivo.

Dierickx e Cool (1989) corroboram ao afirmarem que os gestores concentram seus esforços em encontrar uma posição particular do produto no mercado, em vez de perceberem que a vantagem competitiva é dada pelo reconhecimento e exploração de determinados recursos da firma.

A importância dos recursos para a vantagem competitiva também é dada por Barney (1986), Grant (1991) e Kretzer e Menezes (2006), os quais ressaltam que até mesmo a escolha do posicionamento estratégico, como uma vantagem em diferenciação ou custo, ou a escolha em atuar em um mercado amplo ou restrito (PORTER, 1980, 1985), é determinada pelos recursos da empresa. Uma organização que deseja competir baseada em redução de custos precisa, por exemplo, possuir recursos como tecnologia de processos superior e uma planta de fábrica eficiente.

Barney (1986) ainda ressalva que, dependendo das circunstâncias nas quais a firma se encontra, a análise das informações sobre os 
recursos que ela já controla pode fornecer subsídios para a obtenção de uma vantagem competitiva em longo prazo, e tal vantagem não poderia ser identificada pelo processo de análise tradicional com o foco na indústria em que a organização está inserida.

O processo de planejamento estratégico tem sido objeto de estudo tanto do ponto de vista teórico quanto da sua prática e execução dentro das organizações, pois "a vantagem competitiva da empresa depende das estratégias que ela adota e a manutenção dessa vantagem está baseada no seu processo de valor" (GOHR et al., 2011).

Para Fleury e Fleury (2003), a Visão Baseada em Recursos é a teoria mais adequada às constantes mudanças complexas e dinâmicas pelas quais as organizações passam atualmente, e a abordagem do interior para o exterior das organizações é a mais adequada para a compreensão de como as estratégias são formuladas e postas em prática.

De acordo com Gohr et al. (2011), apesar da importância da Visão Baseada em Recursos, sua implementação ainda apresenta dificuldades, especialmente em relação à avaliação de recursos, sendo essencial o uso de instrumentos que permitam identificar e avaliar os recursos estratégicos da organização.

A empresa objeto de estudo desta pesquisa possui um ambiente organizacional altamente competitivo, caracterizado por várias empresas atuando em nichos de mercado, e atua em um mercado complexo e dinâmico, formado por clientes de companhias multinacionais que estão sujeitos às mudanças macroeconômicas e por uma forte regulamentação governamental. Tal ambiente requer um planejamento estratégico diferenciado e que permita uma verdadeira vantagem competitiva para a organização.

Diante do contexto exposto, tem-se o seguinte problema de pesquisa: como a Visão Baseada em Recursos pode contribuir no processo tradicional de implementação da estratégia organizacional? 
Portanto, este estudo tem como objetivo descrever a inserção da Visão Baseada em Recursos no processo de formação estratégica da empresa objeto de estudo desta pesquisa.

Como contribuição, espera-se que esta pesquisa sirva de base para a integração prática das duas escolas e sirva também como uma base para sugestões de melhorias no atual processo estratégico preconizado pela maioria das organizações, enfatizando que os recursos estratégicos podem ser a base da vantagem competitiva se eles se encaixarem apropriadamente às oportunidades de mercado (PETERAF,1993).

Portanto, este trabalho contribui para a discussão de novas formas de formulação estratégica ao apresentar uma abordagem prática para a construção do mapa estratégico de uma organização, ressaltando a importância da VBR, que pode ser considerada uma teoria importante para suprir algumas limitações da escola do posicionamento, sendo a perspectiva de recursos essencial para complementar a análise tradicional das potencialidades e fraquezas de uma determinada organização, constituindo-se tal junção em um importante fator crítico ao sucesso da firma (AMIT; SCHOEMAKER, 1993; BARNEY; HESTERLY, 2007; GRÖBLER, 2007; PETERAF, 1993). Outro aspecto relevante da pesquisa é a dificuldade ainda demonstrada da implementação prática da VBR, principalmente no que diz respeito à avaliação de recursos (GOHR et al., 2011).

\section{Processo de formulação estratégica}

A estratégia empresarial é um processo organizacional intrínseco à estrutura, ao comportamento e à cultura da organização, sendo dividida em duas fases: formulação e implementação (MINTZBERG; QUINN, 2001).

Para Ansoff e McDonnell (1993), o processo de formulação estipula quais serão os direcionamentos que a organização deve seguir visando o seu crescimento e desenvolvimento contínuo, não constituindo, portanto, uma ação imediata. Barney e Hesterly (2007) corroboram que 
o processo estratégico é um conjunto sequencial de análises e escolhas com o objetivo de alcançar a vantagem competitiva, como mostra a Figura 1.

Figura 1 - Processo de administração estratégica

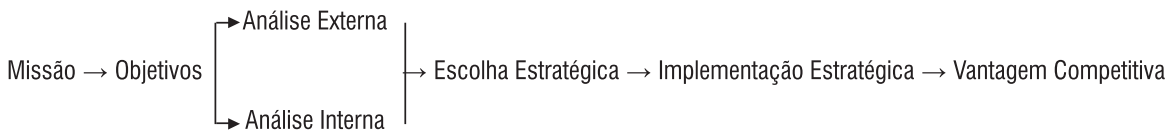

Fonte: Barney e Hesterly (2007).

Tal processo estratégico é fortemente influenciado pela escola do posicionamento, baseado principalmente nos trabalhos de Porter (1980, 1985), pela tentativa de construir modelos de análise de formulação estratégica que priorizam os pontos fortes e fracos e as oportunidades e ameaças do ambiente.

Pavão et al. (2011) sustentam tal afirmação ao considerar Porter como o autor basilar dos estudos e aplicações práticas da formulação e implantação da estratégia organizacional. Os autores acrescentam que, além da predominância da análise do ambiente externo, os trabalhos de Porter contribuíram para o pensamento estratégico ao analisar a cadeia de valor e as relações entre lucratividade em longo prazo e a estrutura do setor.

A definição da missão é o ponto de partida para os direcionamentos futuros da organização, como exposto por Ansoff e McDonnell (1993), sendo a base para a identificação e alcance dos objetivos organizacionais.

A análise do ambiente externo é dividida em várias áreas (tecnológica, social, econômica, ambiental etc.), sendo a mais importante a indústria na qual a organização está inserida (BERTERO et al., 2003; GRÖBLER, 2007). Tal ênfase no ambiente externo é o pressuposto básico dessa escola, segundo a qual a vantagem competitiva de uma organização depende primariamente das condições e características da indústria com a qual ela compete (GRÖBLER, 2007; PORTER, 1980, 1985). 
A análise do ambiente interno, por conseguinte, fica à margem quando se trata da importância do processo estratégico para a escola do posicionamento. A maioria das organizações se contenta em utilizar ferramentas superficiais, como a análise SWOT, para identificar os pontos fortes e fracos da firma (GOHR et al.,2011).

A escolha estratégica, por sua vez, é consequência das análises externa e interna, e define como a organização irá obter a vantagem competitiva, selecionando por meio de qual estratégia a empresa agregará valor a seus clientes. As três estratégias mais comuns são a liderança em custos, a diferenciação de produto e o foco estratégico (PORTER, 1980).

A penúltima etapa é de implementação da estratégia e possui grande importância devido ao fato de executar tudo o que foi planejado anteriormente no processo, podendo a falha nessa etapa prejudicar o alcance dos resultados esperados.

Barney e Hesterly (2007) afirmam que será implementada uma estratégia que respalda a missão da empresa; que seja consistente com seus objetivos; que permita a exploração e a neutralização das ameaças do ambiente.

Tais pressupostos são os balizadores para o processo estratégico da maioria das organizações em todo o mundo, mas eles possuem certas limitações e também são conflitantes com os pressupostos preconizados pela Visão Baseada em Recursos, sendo esta teoria um importante fator complementar para uma maior eficácia na formulação do processo estratégico, suprindo a necessidade de uma análise mais aprofundada de como as firmas obtêm vantagem competitiva.

\section{Implementação da estratégia}

Devido à importância da implementação da estratégia no processo estratégico e ao foco desta pesquisa, um maior detalhamento dessa etapa será realizado a seguir. 


\subsection{Balanced Scorecard}

Para Costa (2006), o BSC é uma ferramenta com o objetivo de tratar da definição e da disposição: (1) das informações-chave para gerenciar a execução da estratégia (mapa estratégico); e (2) dos processos gerenciais que promovem o alinhamento estratégico necessário para tal definição (comunicação, vinculação e referência fundamental).

Para Kaplan e Norton (2004), o Balanced Scorecard possibilita à organização a mensuração de parâmetros críticos que representam sua estratégia para a criação de valor em longo prazo.

Costa (2006) ainda trata o BSC como um instrumento que possibilita a comunicação da estratégia a toda a organização, a fim de orientá-la e integrá-la para o alcance dos objetivos estabelecidos.

O Balanced Scorecard apresenta uma análise da estratégia utilizada para criação de valor em quatro perspectivas (KAPLAN; NORTON,1997):

1. Financeira: definição de objetivos financeiros e metas em longo prazo, visando alcançar um crescimento sustentável da empresa, além de dar retorno aos acionistas da organização.

2. Cliente: definição de como agregar valor para os clientes e aumentar a participação da empresa no mercado e conquistar mais clientes.

3. Processos: definição dos processos críticos da empresa e como melhorá-los continuamente a fim de tornar a empresa mais competitiva, além de atender os objetivos dos acionistas e clientes.

4. Aprendizado e crescimento: definição das estratégias internas para capacitação dos membros da organização e inovação e desenvolvimento de novos produtos e serviços.

Kaplan e Norton (1997) enfatizam que cada perspectiva é apenas uma parte da rede de atividades que a empresa executa, não devendo priorizar somente uma perspectiva, visto que para os objetivos 
estratégicos serem atingidos é necessário que a relação entre causa e efeito entre esses mesmos objetivos seja satisfeita.

O Balanced Scorecard, portanto, se diferencia dos outros modelos de gestão porque permite uma integração entre os objetivos financeiros e não financeiros da organização, explicitando quais são os indicadores de desempenho e as relações de causa e efeito entre os objetivos estratégicos por meio do mapa estratégico que será apresentado a seguir.

\subsection{Visão Baseada em Recursos}

A Visão Baseada em Recursos (VBR) tem como finalidade analisar as características dos recursos internos da organização para entender as condições pelas quais eles geram vantagem competitiva e como essas características mudam ao longo do tempo (BARNEY, 1986, 1991; KRETEZER; MENEZES, 2006; MEDCOF, 2001; PETERAF, 1993), fornecendo uma perspectiva de análise complementar à abordagem externa para concepção de estratégias iniciadas na década de 1960 e depois fortemente influenciada pelos trabalhos de Porter $(1980,1985)$.

Essa teoria teve início com o trabalho de Edith Penrose (1959) intitulado "The theory of the growth of the firm" (GOHR et al., 2011; KRETZER; MENEZES, 2006; PAVÃO, SEHNEM \& HOFFMAN, 2011; PETERAF, 1993). A teoria "penrosiana" assume que as decisões das firmas não são determinadas pelos mercados de fatores e de produtos, e sim pela organização interna dos recursos existentes na organização (KRETZER; MENEZES, 2006).

Esse pressuposto é importante na formulação da estratégia organizacional, visto que o foco na análise externa passa a ter uma posição secundária do processo estratégico, devendo os decisores estratégicos olhar para dentro da firma de forma mais criteriosa, a fim de se estabelecer uma posição privilegiada no que diz respeito à vantagem competitiva. 
Ao longo dos anos, diversos trabalhos buscaram explicar como essa nova abordagem poderia auxiliar os gestores a criar, manter e renovar a vantagem competitiva a partir da análise dos recursos, merecendo destaque para os trabalhos de Amit e Schoemaker (1993), Barney (1986, 1991), Dierickx e Cool (1986), Peteraf (1993), Rumelt (1984) e Wernefelt (1984).

Esses autores procuraram demonstrar uma nova perspectiva de enxergar a organização para o alcance de uma posição competitiva consolidada, explicando a importância de uma avaliação mais aprofundada da perspectiva interna, por meio da análise dos recursos organizacionais, para atingir os objetivos organizacionais.

Nessa lógica, os recursos da firma são definidos como todos os ativos tangíveis e intangíveis que a organização controla e que podem ser usados para criar e implementar estratégias, aumentando a eficiência e eficácia da firma (AMIT; SCHOEMAKER, 1993; BARNEY, 1991; BARNEY; HESTERLY, 2007; WERNEFELT, 1984).

A VBR baseia-se em dois pressupostos básicos: empresas que competem em um mesmo setor podem possuir diferentes conjuntos de recursos e capacidades, sendo tal pressuposto chamado de heterogeneidade de recursos; e que tais diferenças de recursos podem ser duradouras, pois algumas empresas possuem dificuldades de custos para adquirir ou desenvolver certos recursos, caracterizando o pressuposto de imobilidade de recursos. (BARNEY, 1991; BARNEY; HESTERLY, 2007).

Os pressupostos da Visão Baseada em Recursos explicam, segundo essa abordagem, por que firmas que atuam em setores extremamente competitivos podem ter desempenhos totalmente diferentes, mesmo com algumas definições estratégicas "tradicionais", como o posicionamento estratégico (PORTER, 1990), semelhantes.

De acordo com a literatura, os recursos estratégicos devem possuir quatro características, a saber: duráveis, possuindo um longo efeito na posição estratégica da firma; não comercializáveis, não sendo possível 
para os concorrentes comprar facilmente tais recursos; não replicável, não sendo possível para os concorrentes copiar facilmente o recurso; e, por fim, não substituível, pois não é possível para os concorrentes encontrar facilmente um substituto para o recurso (BARNEY, 1991; DIERICKX; COOL, 1989; GRÖBLER, 2007; PETERAF, 1993; WERNEFELT, 1984).

Uma categorização de recursos amplamente aceita na literatura desde os primeiros trabalhos da VBR é a divisão dos recursos em tangíveis e intangíveis, sendo os primeiros os ativos "palpáveis" e de fácil observação, incluindo geralmente os recursos físicos e humanos; e os intangíveis são os mais difíceis de se identificar e quantificar, incluindo os recursos relacionados ao conhecimento organizacional, marca e cultura.

Barney e Hesterly (2007) classificam os recursos em financeiros - dinheiro, de qualquer fonte, que as empresas utilizam para criar e implementar estratégias; físicos - a tecnologia física utilizada na empresa; humanos - treinamento, experiência, visão e habilidades individuais para gerir processos da empresa, incluindo funcionários e gerentes de todos os níveis; e organizacionais - caracterizados pela interação de grupos de pessoas, incluindo os sistemas formais e informais de planejamento, controle e coordenação, além da cultura e reputação da empresa.

A utilização de uma metodologia adequada para identificar e avaliar o potencial estratégico de cada recurso a fim de contribuir para a correta tomada de decisão em relação à quais estratégias a organização deve adotar, garantindo assim uma vantagem competitiva sustentável a partir da análise desse potencial, é essencial para a inserção da Visão Baseada em Recursos no processo de formulação estratégica das empresas (GOHR et al., 2011).

Barney (1991) busca classificar os recursos estratégicos como valiosos, raros e difíceis de imitar, e a partir dessa classificação tais recursos podem ser considerados fontes de vantagem competitiva sustentável para a organização. Barney e Hesterly (2007) aprimoram o modelo de classificação adicionando o fator "organização" como um fator de ajuste para o potencial estratégico de determinado recurso. 
Tal modelo, denominado VRIO (Valor, Raridade, Imitabilidade, Organização), é utilizado para analisar e classificar os recursos estratégicos de uma firma de acordo com os pressupostos da Visão Baseada em Recursos, analisando o potencial dos recursos para gerar vantagens competitivas e identificando as forças e fraquezas internas da organização.

Para uma correta análise baseada em recursos das forças e fraquezas internas da empresa, Barney e Hesterly (2007) elaboraram uma pergunta que identifica se o recurso cumpre cada requisito do modelo VRIO, como mostrado no Quadro 1.

\section{Quadro 1 - Questões-chave do Modelo VRIO}

\begin{tabular}{|l|l|}
\hline \multicolumn{1}{|c|}{ VRIO } & \multicolumn{1}{c|}{ Questões-chave } \\
\hline Valor & $\begin{array}{l}\text { O recurso permite que a empresa explore uma oportunidade } \\
\text { ambiental e/ou neutralize uma ameaça? }\end{array}$ \\
\hline Raridade & $\begin{array}{l}\text { O recurso é controlado atualmente por um pequeno número } \\
\text { de empresas concorrentes? }\end{array}$ \\
\hline Imitabilidade & $\begin{array}{l}\text { As empresas sem os recursos enfrentam uma desvantagem } \\
\text { de custo para obtê-lo ou desenvolvê-lo? }\end{array}$ \\
\hline Organização & $\begin{array}{l}\text { As outras políticas e os procedimentos da empresa estão } \\
\text { organizados para dar suporte à exploração de seus recursos } \\
\text { valiosos, raros e custosos para imitar? }\end{array}$ \\
\hline
\end{tabular}

Fonte: Barney e Hesterly (2007).

A seguir, é explicitada cada uma das perspectivas do modelo VRIO (BARNEY; HESTERLY, 2007).

Valor: o recurso só tem valor se permitir que a empresa explore uma oportunidade do ambiente ou neutralize uma ameaça, que, nesse caso, constitui uma força para a empresa. Se o recurso não possuir essa característica, ele é considerado uma fraqueza

Raridade: um recurso valioso só é fonte de vantagem competitiva se for controlado por poucos concorrentes. Quando um recurso é valioso, 
mas não é raro, ele proporciona paridade competitiva no setor, ou seja, é um "item de sobrevivência", mas não gera vantagem competitiva.

Imitabilidade: para gerar vantagem competitiva sustentável, um recurso, além de ser valioso e raro, deve ser difícil de ser imitado.

Organização: a perspectiva organização atua como um fator de ajuste, pois não basta ter recursos valiosos, raros e difíceis de imitar; a organização deve explorá-los para que gerem vantagem competitiva sustentável, mediante políticas e procedimentos organizacionais que deem suporte a esses recursos.

O Quadro 2 mostra a classificação do potencial estratégico dos recursos de acordo com a classificação VRIO.

Quadro 2 - Avaliação de recursos segundo o modelo VRIO

\begin{tabular}{|l|c|c|c|c|c|}
\hline Um recurso é: & & & & & \\
\hline Valioso? & Raro? & $\begin{array}{c}\text { Custoso } \\
\text { de imitar? }\end{array}$ & Explorado? & $\begin{array}{c}\text { Implicações } \\
\text { competitivas }\end{array}$ & Força/Fraqueza \\
\hline Não & Não & Não & Não & $\begin{array}{c}\text { Desvantagem } \\
\text { Competitiva }\end{array}$ & Fraqueza \\
\hline Sim & Não & Não & Sim & $\begin{array}{c}\text { Paridade } \\
\text { Competitiva }\end{array}$ & Força \\
\hline Sim & Sim & Não & Sim & $\begin{array}{c}\text { Vantagem } \\
\text { Competitiva } \\
\text { Temporária }\end{array}$ & Força Distintiva \\
\hline $\operatorname{Sim}$ & $\operatorname{Sim}$ & Sim & Sim & $\begin{array}{c}\text { Vantagem } \\
\text { Competitiva } \\
\text { Sustentável }\end{array}$ & $\begin{array}{c}\text { Força Distintiva } \\
\text { Sustentável }\end{array}$ \\
\hline
\end{tabular}

Fonte: Barney e Hesterly (2007).

Se o recurso não apresenta nenhum aspecto do VRIO, ele acarreta desvantagem competitiva para a organização e acaba sendo uma fraqueza organizacional, devendo a organização melhorar o desempenho do recurso ou evitar usá-lo ao implementar uma estratégia organizacional.

Se o recurso é valioso, mas não é raro, gera uma situação de paridade competitiva. Barney e Hesterly (2007) afirmam que recursos 
valiosos, mas não raros, são considerados forças organizacionais, porque apesar de não criarem vantagem competitiva, a sua não exploração pode colocar uma empresa em desvantagem competitiva.

Por fim, o recurso somente fornecerá algum tipo de vantagem competitiva à organização se for valioso, raro e explorado pela organização ao mesmo tempo. Se for fácil de imitar, os concorrentes poderão adquiri-lo em um prazo de tempo curto e a vantagem competitiva será temporária. Se for difícil de imitar, a vantagem que a organização terá em explorar esse recurso se perpetuará ao longo do tempo.

O modelo VRIO é de vital importância para auxiliar os gestores a tomar decisões relativas a desenvolver e adquirir determinados recursos que podem gerar uma vantagem competitiva, contribuindo no processo de identificar quais recursos são importantes para a firma e quais não são (BARNEY, 1991; PETERAF, 1993).

A partir dessa visão estratégica, a vantagem competitiva é criada, mantida e renovada a partir dos recursos organizacionais, sendo realizada por meio de acumulação interna dos recursos ou adquirindoos no mercado (FOSS, 1993).

\section{Metodologia}

Este trabalho caracteriza-se como uma pesquisa qualitativa, visto que os dados foram obtidos por meio do contato direto e interativo dos pesquisadores com a situação objeto de estudo, sendo a interpretação do fenômeno estudado resultante das perspectivas dos participantes em relação à situação observada (NEVES, 1996).

Ele pretende explicitar as etapas do processo estratégico da Bioconsultants, enfatizando a união da escola do Posicionamento e da Visão Baseada em Recursos no decorrer desse processo. Trata-se, portanto, de uma pesquisa exploratória descritiva (TRIPODI et al., 1981), subtipo estudo de caso (BRUYNE, 1991).

Marconi e Lakatos (2007) argumentam que o estudo de caso tem como característica a capacidade de proporcionar ao pesquisador 
a utilização de uma grande variedade de instrumentos para a coleta de evidências do fenômeno a ser estudado, como a utilização de documentos, entrevistas e observações.

Devido ao objetivo desta pesquisa de explicitar a Visão Baseada em Recursos no processo estratégico, o estudo de caso será único, visto que somente a empresa objeto da pesquisa utilizou de tal abordagem na formulação da estratégia organizacional no seu setor de atuação.

Os elementos de pesquisa compreendem o sócio-diretor administrativo e o gerente administrativo da Bioconsultants, ambos responsáveis pela tomada de decisão e estabelecimento das políticas organizacionais relacionadas ao planejamento estratégico.

Os dados primários foram coletados a partir de análise documental concedida pela empresa para identificar quais as etapas do planejamento estratégico foram realizadas; e por meio de entrevistas semiestruturadas com o sócio-diretor administrativo e o gerente administrativo da Bioconsultants a identificação dos recursos estratégicos da organização, e ainda por meio de aplicação de questionários com escala likert para a classificação dos recursos estratégicos.

O processo de coleta de dados se deu no período de outubro a novembro de 2013 e contemplou as seguintes etapas: pesquisa bibliográfica sobre a literatura, pesquisa qualitativa documental, realização das entrevistas semiestruturadas com os gestores da empresa e aplicação dos questionários.

A pesquisa documental abrangeu o material de sensibilização, as apresentações das reuniões para definição da missão, visão e análise SWOT, além dos materiais de definição dos cenários e do posicionamento estratégico da organização.

As entrevistas semiestruturadas foram realizadas para a identificação dos recursos estratégicos, sendo utilizadas quatro perguntas abertas a fim de investigar quais os recursos utilizados na tomada de decisão estratégica e que permitem à empresa ter um aumento na receita ou uma redução nos custos operacionais. 
Após a identificação, foram aplicados dois questionários utilizando escala likert para obter a classificação dos recursos estratégicos da organização com base no método VRIO (BARNEY; HERSTERLY, 2007).

No primeiro questionário, para cada recurso estratégico identificado, os gestores responderam a três perguntas, a fim de identificar se os recursos eram valiosos, raros e difíceis de imitar (as três primeiras características do VRIO), classificando as respostas em uma escala likert com quatro classificações: (1) concordo plenamente; (2) concordo; (3) discordo; e (4) discordo plenamente. A classificação em quatro respostas foi estabelecida para facilitar a classificação de acordo com o método VRIO, que só considera "sim" e "não" para definir as implicações competitivas dos recursos, sendo as duas primeiras classificações do questionário - "concordo plenamente" e "concordo" - caracterizadas como "sim"; e "discordo" e "discordo plenamente" caracterizadas como "não".

No segundo questionário, os gestores responderam a uma pergunta para identificar se a organização possui políticas e procedimentos para explorar os recursos estratégicos identificados (última característica do VRIO), classificando as respostas em uma escala likert com quatro classificações: (1) sempre; (2) quase sempre; (3) eventualmente; e (4) nunca. As duas primeiras classificações (sempre e quase sempre) foram caracterizadas como "sim", e as duas últimas (eventualmente e nunca) como "não", de acordo com o método VRIO.

Após coletadas as informações, os dados foram analisados e interpretados com a intenção de estabelecer uma relação com as ações desenvolvidas na Bioconsultants relacionadas ao planejamento estratégico e à revisão da literatura do tema, com a finalidade de descrever de forma fidedigna as etapas do processo estratégico da empresa, sendo as contribuições da Visão Baseada em Recursos analisadas contrapondo o processo em questão com a literatura sobre o tema. 


\section{Análise dos resultados}

A Bioconsultants Consultoria em Recursos Naturais e Meio Ambiente possui sede em Natal, no Rio Grande do Norte, e oferece serviços da mais alta qualidade a investidores e operadores nacionais e internacionais no ramo de desenvolvimento sustentável.

O processo de formulação do planejamento estratégico foi realizado com o interesse de atender à crescente demanda de atividades de natureza técnica no licenciamento de empreendimentos de pequeno, médio e grande porte, além de atuar na elaboração de estudos de viabilidade ambiental e gestão de parques eólicos.

O processo de formulação estratégica começou com a sensibilização da alta administração da organização, bem como dos demais funcionários, a fim de ressaltar a importância do planejamento estratégico para a organização e a metodologia que seria utilizada para a implementação do processo.

O passo seguinte à sensibilização foi a definição da missão e da visão organizacional da empresa por meio da técnica de brainstorming (tempestade de ideias). Para tanto, ocorreu uma reunião para a definição da missão, e outra posterior para a definição da visão, nas quais se reuniram todos os funcionários da empresa e houve uma breve explicação da definição dos conceitos e quais são os benefícios de se estabelecer uma missão e visão para a organização, com exemplos reais de outras empresas.

Após a definição dos elementos balizadores do planejamento estratégico, foram apresentados os cenários relativos ao passado, presente e futuro, considerando seis agentes que impactam no desempenho organizacional.

A partir dos cenários, pôde-se constatar que a empresa se encontrava em uma posição delicada do ponto de vista estratégico, pois concentrava os seus projetos realizados em apenas um serviço específico (energia eólica), em apenas um estado brasileiro (Rio Grande do Norte), apesar da presença de várias empresas atuando na região. 
Posteriormente, foram realizadas duas reuniões para a construção da análise SWOT da empresa, utilizando-se de brainstorming com a presença dos funcionários, baseando-se na apresentação dos cenários na etapa anterior e na experiência e vivência do cotidiano organizacional, para a identificação das forças, fraquezas, oportunidades e ameaças.

A partir do brainstorming, o gerente administrativo organizou os principais pontos destacados em cada perspectiva, mostrados a seguir:

- Forças: equipe sólida, inovadora, capacitada e experiente; qualidade nos serviços.

- Fraquezas: não delimitação das atividades dos funcionários; falta de divulgação nas mídias.

- Oportunidades: mercado de energia limpa em crescimento; novos segmentos de mercado.

- Ameaças: falta de mão de obra qualificada; burocracia no órgão ambiental.

Aetapa final do processo tradicional foi a escolha do posicionamento estratégico da empresa (PORTER,1980). Para tal finalidade, sucedeuse uma reunião com o sócio-diretor administrativo da empresa, com o gerente administrativo e com o gerente de projetos da organização.

Apartir do exposto nos cenários e na análise SWOT, visando também o alcance da visão organizacional, os principais gestores definiram que o posicionamento estratégico seria o "foco" em um determinado segmento de linhas de produtos/serviços, com o pressuposto de que a empresa pode ofertar melhor esses serviços do que as concorrentes.

Após o processo tradicional, partindo para a Visão Baseada em Recursos, obteve-se a identificação dos recursos estratégicos da organização de acordo com a percepção do gestor, bem como a classificação dos recursos. Em seguida, foi realizada a avaliação dos recursos baseada no modelo VRIO (BARNEY; HESTERLY, 2007), como mostrada no Quadro 3, e a avaliação do potencial competitivo da empresa baseado no modelo. 
Marcelo Hugo de Medeiros Bezerra, Miguel Eduardo Moreno Añez, Josué Vitor de Medeiros Júnior, César Augusto Barreto da Silva

Quadro 3 - Identificação e classificação dos recursos estratégicos da Bioconsultants

\begin{tabular}{|c|c|c|c|c|}
\hline Recurso & Tipo & Tangibilidade & $\begin{array}{l}\text { Posição } \\
\text { competitiva }\end{array}$ & Caracterização \\
\hline Funcionários & Humano & Tangível & $\begin{array}{l}\text { Desvantagem } \\
\text { competitiva }\end{array}$ & Fraqueza \\
\hline $\begin{array}{l}\text { Reputação da } \\
\text { organização }\end{array}$ & Organizacional & Intangível & $\begin{array}{l}\text { Desvantagem } \\
\text { competitiva }\end{array}$ & Fraqueza \\
\hline $\begin{array}{l}\text { Know-how em } \\
\text { licenciamento } \\
\text { ambiental }\end{array}$ & Humano & Intangível & $\begin{array}{l}\text { Vantagem } \\
\text { competitiva } \\
\text { sustentável }\end{array}$ & $\begin{array}{l}\text { Força e } \\
\text { competência } \\
\text { distintiva } \\
\text { sustentável }\end{array}$ \\
\hline $\begin{array}{l}\text { Catálogo de } \\
\text { serviços }\end{array}$ & Organizacional & Tangível & $\begin{array}{l}\text { Desvantagem } \\
\text { competitiva }\end{array}$ & Fraqueza \\
\hline Projetos técnicos & Organizacional & Tangível & Paridade & Força \\
\hline $\begin{array}{l}\text { Projetos de ação } \\
\text { social }\end{array}$ & Organizacional & Tangível & $\begin{array}{l}\text { Vantagem } \\
\text { competitiva } \\
\text { temporária }\end{array}$ & $\begin{array}{l}\text { Força e } \\
\text { competência } \\
\text { distintiva }\end{array}$ \\
\hline $\begin{array}{l}\text { Nível de acesso } \\
\text { aos órgãos } \\
\text { ambientais }\end{array}$ & Organizacional & Intangível & $\begin{array}{l}\text { Vantagem } \\
\text { competitiva } \\
\text { sustentável }\end{array}$ & $\begin{array}{l}\text { Força e } \\
\text { competência } \\
\text { distintiva } \\
\text { sustentável }\end{array}$ \\
\hline Clientes & Humano & Tangível & Paridade & Força \\
\hline $\begin{array}{l}\text { Conscientização } \\
\text { da existência da } \\
\text { empresa }\end{array}$ & Humano & Intangível & $\begin{array}{l}\text { Desvantagem } \\
\text { competitiva }\end{array}$ & Fraqueza \\
\hline Caixa & Financeiro & Tangível & $\begin{array}{l}\text { Desvantagem } \\
\text { competitiva }\end{array}$ & Fraqueza \\
\hline $\begin{array}{l}\text { Parcerias } \\
\text { estratégicas }\end{array}$ & Organizacional & Tangível & Paridade & Força \\
\hline $\begin{array}{l}\text { Nível de } \\
\text { divulgação }\end{array}$ & Organizacional & Intangível & $\begin{array}{l}\text { Desvantagem } \\
\text { competitiva }\end{array}$ & Fraqueza \\
\hline $\begin{array}{l}\text { Qualificação dos } \\
\text { funcionários }\end{array}$ & Humano & Intangível & $\begin{array}{l}\text { Desvantagem } \\
\text { competitiva }\end{array}$ & Fraqueza \\
\hline
\end{tabular}

Fonte: Dados da pesquisa (2013).

Os 13 recursos estratégicos identificados pelo gestor da organização foram classificados em recursos financeiros, físicos, individuais e organizacionais. 
De acordo com a classificação, $54 \%$ dos recursos são tangíveis (sete recursos) e $46 \%$ são intangíveis (seis recursos). Sete recursos (54\%) foram classificados como organizacionais; cinco recursos (38\%) como humanos; um recurso $(8 \%)$ foi caracterizado como financeiro e foi classificado como físico.

No que diz respeito à posição competitiva da organização gerada pelos recursos, a classificação foi a seguinte: sete recursos (54\%) deixam a organização em desvantagem competitiva; três recursos (23\%) fornecem a empresa uma posição de paridade competitiva; um recurso (8\%) gera vantagem competitiva temporária à organização; e apenas dois recursos (15\%) geram vantagem competitiva sustentável para a empresa.

Com base na classificação, pode-se notar que a organização apresenta uma posição frágil no que diz respeito aos seus recursos, pois mais da metade dos recursos estratégicos identificados gera desvantagem competitiva à organização. Desses que geram desvantagem competitiva, três recursos são humanos, ou seja, $60 \%$ dos recursos humanos geram desvantagem competitiva para a organização. Esse elevado número pode refletir a falta de políticas direcionadas aos funcionários da empresa no intuito de qualificá-los e de os deixarem satisfeitos.

Apenas três recursos (23\%) identificados geram alguma vantagem competitiva para a empresa. Dois deles, know-how em licenciamento ambiental e nível de acesso aos órgãos ambientais, geram vantagem competitiva sustentável à organização. Tais recursos são relevantes para um elevado desempenho de uma empresa no segmento de consultoria ambiental, e a exploração contínua desses recursos pode diminuir as ameaças do ambiente externo e permite explorar oportunidades do ambiente de negócio.

A partir dos resultados da formulação do planejamento estratégico tradicional, principalmente da visão, da análise de cenários e SWOT e do posicionamento estratégico, somados à classificação do potencial competitivo dos recursos estratégicos, deu-se o início da construção do Balanced Scorecard da empresa. 
Por causa da fragilidade no que diz respeito à posição competitiva da organização de acordo com o modelo VRIO, a construção do mapa estratégico (KAPLAN; NORTON, 2004) e dos consequentes objetivos estratégicos organizacionais priorizou a otimização dos recursos estratégicos identificados pelo principal gestor da empresa.

Com o objetivo de atingir tal finalidade, para cada recurso estratégico identificado, independentemente da sua caraterização como fonte de vantagem competitiva, foi relacionado pelo menos um objetivo estratégico do mapa estratégico. A relação entre os recursos estratégicos e seus respectivos objetivos estratégicos é exposta no Quadro 4.

\section{Quadro 4 - Relação entre recursos e objetivos estratégicos do BSC}

\begin{tabular}{|l|l|}
\hline $\begin{array}{l}\text { Recursos estratégicos } \\
\text { - VBR }\end{array}$ & Objetivos estratégicos - BSC \\
\hline Funcionários & $\begin{array}{l}\text { Maior participação dos funcionários no negócio. } \\
\text { Proporcionar maior satisfação no ambiente de trabalho dos } \\
\text { funcionários. }\end{array}$ \\
\hline $\begin{array}{l}\text { Reputação da } \\
\text { organização }\end{array}$ & Melhorar relacionamento com clientes. \\
\hline $\begin{array}{l}\text { Know-how em } \\
\text { licenciamento ambiental }\end{array}$ & Maximizar a realização de treinamentos para funcionários. \\
\hline $\begin{array}{l}\text { Catálogo de serviços } \\
\text { Projetos técnicos }\end{array}$ & $\begin{array}{l}\text { Desenvolver o processo de inovação; Aumentar market - share } \\
\text { em novos segmentos. }\end{array}$ \\
\hline Projetos de ação social & Melhorar o sistema de gestão de projetos. \\
\hline $\begin{array}{l}\text { Nível de acesso aos } \\
\text { órgãos ambientais }\end{array}$ & Fortalecer parcerias estratégicas. \\
\hline Clientes & $\begin{array}{l}\text { Melhorar relacionamento com clientes; Fornecer um serviço de } \\
\text { alto padrão de qualidade. }\end{array}$ \\
\hline $\begin{array}{l}\text { Conscientização da } \\
\text { existência da empresa }\end{array}$ & Aumentar divulgação nas mídias e eventos. \\
\hline Caixa & Melhorar fluxo de caixa. \\
\hline Parcerias estratégicas & Fortalecer parcerias estratégicas. \\
\hline Nível de divulgação & Aumentar divulgação nas mídias e eventos. \\
\hline $\begin{array}{l}\text { Qualificação dos } \\
\text { funcionários }\end{array}$ & Maximizar a realização de treinamento para funcionários. \\
\hline
\end{tabular}

Fonte: Dados da pesquisa (2013). 
Com os objetivos estratégicos definidos, a fim de potencializar cada recurso estratégico da organização, o último passo na formulação estratégica ocorreu com a classificação dos objetivos em cada perspectiva do Balanced Scorecard, bem como com a inter-relação dos objetivos estratégicos, como mostrado na Figura 2, visando atingir a visão organizacional a partir da exploração efetiva dos recursos estratégicos e das oportunidades advindas do ambiente organizacional.

Figura 2 - Mapa estratégico da Bioconsultants

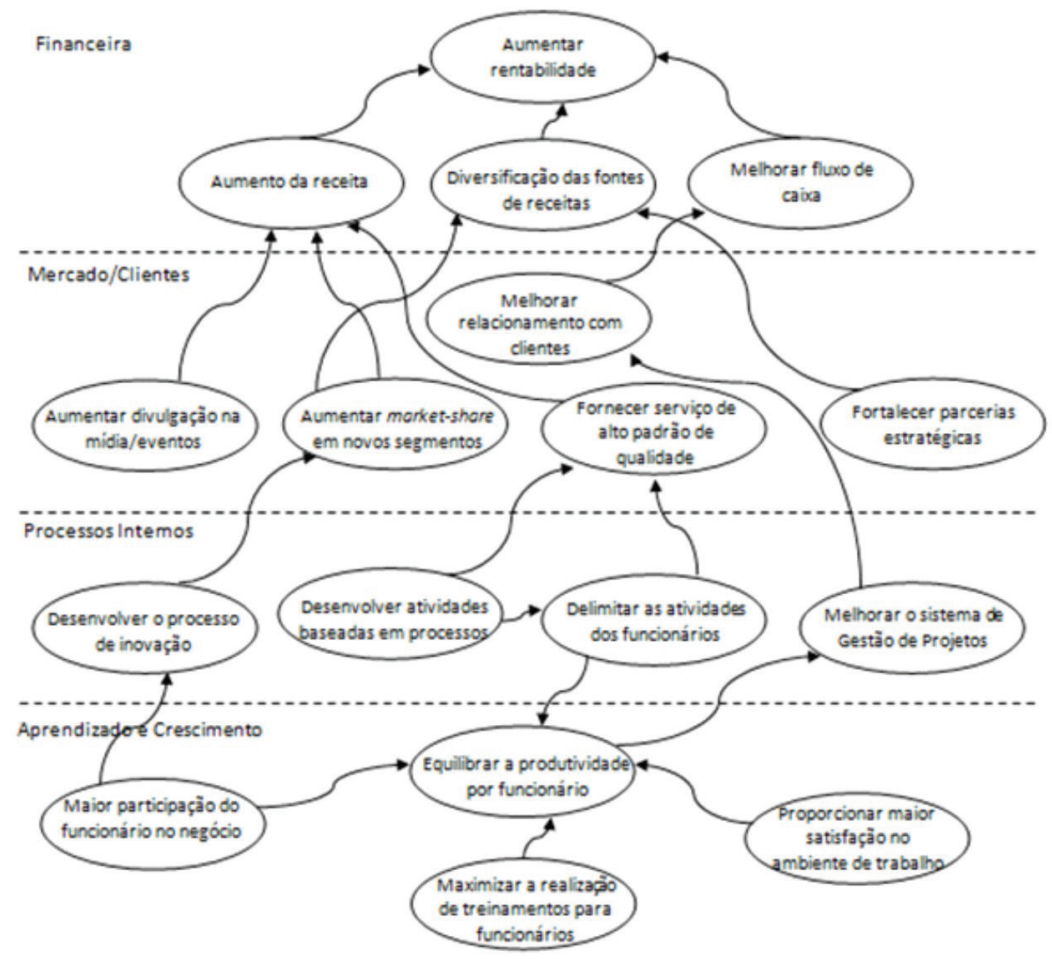

Fonte: Dados da pesquisa (2013).

A partir da caracterização dos recursos e da inter-relação dos objetivos estratégicos, tem-se que os objetivos do mapa - "Fortalecer parcerias estratégicas" e "Maximizar a realização de treinamento para 
funcionários" - apresentam elevada importância para a organização, pois além dos recursos basilares desses objetivos serem classificados como fonte de vantagem competitiva, encontram-se em posições-chave no mapa estratégico.

A partir dos resultados e da análise do processo estratégico da Bioconsultants, algumas contribuições da Visão Baseada em Recursos podem ser apontadas. O primeiro benefício se refere a essa etapa de relacionamento entre os recursos estratégicos e os objetivos estratégicos do Balanced Scorecard, fazendo com que o foco na perspectiva interna caracterizadora da Visão Baseada em Recursos amenize a fragilidade na elaboração do BSC no que diz respeito a uma análise excessiva do ambiente externo.

Relacionar cada objetivo estratégico a um recurso estratégico identificado anteriormente no processo potencializa os pontos fortes de cada abordagem por meio da união de uma análise criteriosa tanto do ponto de vista interno quanto externo na construção do mapa estratégico da organização, sendo tal etapa importante na elaboração das ações e dos indicadores estratégicos da organização.

Da mesma forma, a Visão Baseada em Recursos auxilia os gestores a priorizarem em que perspectiva do Balanced Scorecard deve ser feita as principais ações no ciclo do planejamento estratégico.

Neste estudo, percebe-se que a perspectiva de "aprendizado e crescimento" merece uma atenção especial, pois recursos humanos estratégicos da organização não estão sendo explorados pela empresa, devendo os objetivos estratégicos dessa perspectiva reverterem tal situação de baixa competitividade.

A partir da análise SWOT da organização, por exemplo, os gestores podem ter uma visão de que a empresa está em uma posição competitiva ótima, tendo a qualidade dos seus funcionários como ponto forte e diferencial, mas pela análise do modelo VRIO ficou constatado que a organização não explora esse recurso, constituindo uma fraqueza organizacional. 
Assim, a junção de uma análise do processo estratégico tradicional, como a análise SWOT, e uma análise da VBR por meio do método VRIO, constitui-se a melhor forma de analisar o real poder competitivo da organização, de modo que este último método de análise atue como um modelo que comprova se os pontos elencados na análise SWOT são realmente causadores ou não de vantagem competitiva para a organização.

A maior percepção dos gestores em relação a ter um maior foco nos recursos como provenientes de vantagem competitiva também é outro benefício da Visão Baseada em Recurso no presente estudo. Por meio das entrevistas e da análise do processo, pôde-se constatar que a análise competitiva dos recursos permitiu que os gestores tivessem um olhar para dentro da organização de forma mais criteriosa, não somente dando prioridade para análises de mercado ou outros componentes externos à organização. Dierickx e Cool (1989) corroboram ao afirmarem que os gestores concentram seus esforços em encontrar uma posição particular do produto no mercado em vez de perceberem que a vantagem competitiva é dada pelo reconhecimento e exploração de determinados recursos da firma.

\section{Conclusão}

A formulação da estratégia tradicional focando somente no ambiente externo à organização já não atende às necessidades competitivas das organizações, principalmente as que estão inseridas em mercados complexos e competitivos, exigindo o emprego de uma nova teoria na formulação estratégica que atenda a tais requisitos (BARNEY, 1986; DIERICKX; COOL, 1989; FLEURY; FLEURY, 2003; GRÖBLER, 2007; PETERAF, 1993; WERNEFELT, 1984).

O processo estratégico na empresa objeto de estudo desta pesquisa vai ao encontro dessa nova necessidade de formulação estratégica, possibilitando a junção de preceitos de duas escolas tradicionais da estratégia, mas que não são empregadas de forma conjunta comumente. 
A análise dos recursos internos da organização permitiu identificar quais recursos da organização podem ser os balizadores das estratégias a serem postas em prática e qual o benefício real que cada recurso poderia oferecer à empresa para implementar tais estratégias.

A análise dos recursos estratégicos com o uso do modelo VRIO (BARNEY; HESTERLY, 2007) identificou uma baixa posição competitiva da organização, pois mais de $50 \%$ dos recursos estratégicos identificados geram desvantagem competitiva para a organização, onde metade desses são recursos referentes à capacidade humana, sendo fato relevante para o melhoramento das atividades organizacionais a partir das ações estratégicas a serem estabelecidas.

Como benefícios da adoção da Visão Baseada em Recursos no processo estratégico tradicional, tem-se a construção do mapa estratégico do Balanced Scorecard (KAPLAN; NORTON, 1997) a partir da análise dos recursos internos da firma, visto que a definição dos objetivos estratégicos e seus inter-relacionamentos não consideram as potencialidades e fraquezas sob uma perspectiva interna da organização, possibilitando assim uma análise mais fidedigna dos meios pelos quais a organização irá alcançar seus objetivos em longo prazo.

Outro benefício constatado no trabalho diz respeito ao uso da metodologia VRIO para constatar a real situação competitiva da empresa, complementando a análise realizada pelo modelo SWOT, mitigando a análise interna superficial dessa última ferramenta de gestão, apurando se os pontos levantados pela equipe podem ser geradores de uma vantagem competitiva sustentável.

Outro ponto positivo da união das duas abordagens é a possibilidade de uma análise complementar da escolha do posicionamento competitivo e a análise da classificação do potencial estratégico de cada recurso, devendo a empresa relacionar futuramente quais são os recursos estratégicos que ela deve adquirir ou explorar de forma mais consistente para que ela atue de forma diferenciada no posicionamento de mercado estabelecido. 
O último benefício, mas não menos importante, é a percepção dos gestores para uma nova forma de formulação estratégica e de como alcançar a vantagem competitiva sustentável no setor de uma forma não convencional por meio da análise e exploração de seus recursos, necessitando de um exame sistemático da situação competitiva da empresa.

\section{Referências}

AMIT, R.; SCHOEMAKER, P.J.H. Strategic assets and organizational rents. Strategic Management Journal, Chicago, v. 14, n.1, p. 33-47, Jan. 1993.

ANSOFF, H. I; MCDONNELL, E. J. Implantando a administração estratégica. São Paulo: Atlas, 1993.

BARNEY, J. B. Strategic factor markets. Management Science, Catonsville, v. 32, n.10, p. 1.231-1.241, Oct. 1986.

. Firm resources and sustained competitive advantage.

Journal of Management, Cambridge, v. 17, n.1, p. 99-120, Mar .1991.

BARNEY, J. B.; HESTERLY, W.S. Administração estratégica e vantagem competitiva. São Paulo: Pearson Prentice Hall, 2007.

BERTERO, C. O.; VASCONCELOS, F. C.; BINDER, M. P. Estratégia empresarial: a produção científica brasileira entre 1991 e 2002.

Revista de Administração de Empresas, São Paulo, v. 43, n.4, p.4862, out./dez. 2003.

BRUYNE, P. de; HERMAN, J.; DE SCHOUTHEETE, M. Dinâmica da Pesquisa em Ciências Sociais - os pólos da prática metodológica. Rio de Janeiro: Livraria Francisco Alves, 1991.

COSTA, A. P. P. Balanced scorecard: conceitos e guia de implementação. São Paulo: Atlas, 2006. 
DIERICKX, I.; COOL, K. Asset stock accumulation and sustainability of competitive advantage. Management Science, Catonsville, v. 33, n.12, p. 1504-1511, Dec. 1987.

FLEURY, A. C. C.; FLEURY, M. T. L. Estratégias competitivas e competências essenciais: perspectivas para a internacionalização da indústria no Brasil. Gestão \& Produção, São Carlos, v.10, n.2, p. 129144, ago.. 2003.

FOSS, N. J. Theories of the firm: contractual and competence perspectives. Journal of Evolutionary Economics, New York, v. 3, p. 127-144, Sept. 1993.

GOHR, F.C.; SANTOS, L.C.; BURIN, C.B.; MARQUES, M.S.; ARAI, R.M. Recursos estratégicos e vantagem competitiva: aplicação do modelo VRIO em uma organização do setor sucroalcooleiro. Revista Gestão Organizacional, Santa Catarina, v.4, n.1, p.49-70, jan./jun. 2011.

GRANT, R. M. The resource-based theory of competitive advantage: implications for strategy formulation. California Management Review, California, Spring 91, v. 33, n.3, p. 114-135, Mar. 1991.

GRÖBLER, A. A dynamic review on strategic resources and capabilities applied to an example from the manufacturing strategy literature. Journal of Manufacturing Technology Management, Bingley, v.18, n.3, p. 250-266, 2007.

KAPLAN, R.; NORTON, D. A estratégia em ação: Balanced scorecard. 13. ed. Rio de Janeiro: Campus, 1997.

. Mapas estratégicos: convertendo ativos intangíveis em resultados tangíveis. Rio de Janeiro: Elsevier, 2004.

KRETZER, J.; MENEZES, E. A. A importância da visão baseada em recursos na explicação da vantagem competitiva. Revista de Economia Mackenzie, São Paulo, v. 4, n.4, p.63-87, 2006. 
MARCONI, M. A.; LAKATOS, E. M. Fundamentos de metodologia científica. 6. ed. São Paulo: Atlas, 2007.

MEDCOF, J. W. Resource-based strategy and managerial power in networks of internationally dispersed technology units. Strategic Management Journal, Chicago, v.22, n.11, p. 999-1012, Mar. 2001.

MINTZBERG, H.; QUINN, J. B. O processo da estratégia. 3.ed. Porto Alegre: Bookman, 2001.

NEVES, José Luis. Pesquisa qualitativa - características, usos e possibilidades. Caderno de Pesquisa em Administração, São Paulo, v.1, n.3, jul/dez. 1996.

PAVÃO, Y.M.P., SEHNEM, S., \& HOFFMAN V. E. Análise dos recursos organizacionais que sustentam a vantagem competitiva. Revista de Administração, São Paulo, v. 46, n.3, p.228-242, jul/ago/set 2011.

PENROSE, E. The theory of the growth of the firm. 40 ed. Oxford: Blackwell, 1959.

PETERAF, M. A. The cornerstones of competitive advantage: a resource-based view. Strategic Management Journal, Chicago, v.14, n.3, p. 179-191, Mar. 1993.

PORTER, M. E. Competitive advantage. New York: Free Press, 1985.

. Competitive strategy: techniques for analyzing industries and competitors. New York: Free Press, 1980.

RUMELT, R. P. Towards a strategic theory of the firm. In: LAMB, R. B. (Ed.). Competitive strategic management, New Jersey, Englewood Cliffs: Prentice-Hall, v. 17 n. 1, p. 155-171, 1984.

TRIPODI, T.; FELIN, P.; MEYER, H. Análise da pesquisa social. Petrópolis: Ed. Alves, 1981.

VASCONCELOS, F.C.; CYRINO, A.B. Vantagem competitiva: os modelos teóricos atuais e a convergência entre estratégia e teoria 
organizacional. Revista de Administração de Empresas, São Paulo, v. 40, n. 4 , p. 20-37, out./dez. 2000.

WERNERFELT, B. A resource-based view of the firm. Strategic

Management Journal, Chicago, v.5, n.2, p. 171-180, Apr./Jun. 1984.

Artigo recebido em: 11/02/2015

Aprovado em: 24/08/2015 